\title{
IN VITRO ANTIFUNGAL ACTION OF DIFFERENT SUBSTANCES OVER MICROWAVED-CURED ACRYLIC RESINS
}

\author{
Henrique MONTAGNER ${ }^{1}$, Francisco MONTAGNER ${ }^{2}$, Katia Olmedo BRAUN ${ }^{3}$, Paulo Edelvar Correa PERES 4 , \\ Brenda Paula Figueiredo de Almeida GOMES ${ }^{5}$
}

\author{
1- DDS, Graduate student, Department of Restorative Dentistry, Federal University of Santa Maria, Santa Maria, RS, Brazil. \\ 2- DDS, MSc, Graduate Student, Department of Restorative Dentistry, Piracicaba Dental School, Endodontic Division, University of Campinas, \\ Piracicaba, SP, Brazil. \\ 3- DDS, MSc, PhD, Associate Professor, Department of Restorative Dentistry, Federal University of Santa Maria, Santa Maria, RS, Brazil. \\ 4- DDS, MSc, PhD, Associate Professor, Department of Microbiology and Parasitology, Federal University of Santa Maria, Santa Maria, RS, Brazil. \\ 5- DDS, MSc, PhD, Associate Professor, Department of Restorative Dentistry, Endodontic Division, Piracicaba Dental School, University of Campinas, \\ Piracicaba, SP, Brazil.
}

Corresponding address: Dr. Brenda Paula Figueiredo de Almeida Gomes - Área de Endodontia - Faculdade de Odontologia de Piracicaba - UNICAMP. Avenida Limeira, 901 - Bairro Areião 13414-018 - Piracicaba, SP - Brasil - e-mail: bpgomes@fop.unicamp.br

Received: July 24, 2008 - Modification: January 10, 2009 - Accepted: January 18, 2009

\begin{abstract}
$O$ bjective: The presence of Candida albicans on the surfaces of denture-base acrylic resins is strongly related to the development of oral stomatitis. This study evaluated the antifungal action of different agents over microwave-cured acrylic resin without polishing specimens previously contaminated with Candida albicans. Material and Methods: Sixty specimens were immersed in BHI broth previously inoculated with the yeast and stored for $3 \mathrm{~h}$ at $37^{\circ} \mathrm{C}$. They were divided into 5 experimental groups ( $\left.\mathrm{n}=10\right)$ : $\mathrm{G} 1: 2 \%$ chlorhexidine solution (10 min); G2: $0.5 \%$ sodium hypochlorite (10 min); G3: modified sodium hypochlorite (10 min); G4: effervescent agent ( $5 \mathrm{~min})$; G5: hydrogen peroxide 10v (30 min). The specimens of the control group 1 (C1) were not disinfected. Ten additional specimens of the control group 2 (C2) were not infected with the yeast, aiming to check the asepsis during the experiment. The disinfection agents were neutralized and the acrylic resin specimens were immersed in BHI Broth for $24 \mathrm{~h}$. Culture media turbidity was evaluated spectrophotometrically according to the transmittance degree, i.e. the higher the transmittance the stronger the antimicrobial action. Statistical analysis was performed (Kruskal-Wallis Test, $\mathrm{p}<0.05$ ). Results: The results, represented by the medians, were: $\mathrm{G} 1=40 ; \mathrm{G} 2=100 ; \mathrm{G} 3=100 ; \mathrm{G} 4=90 ; \mathrm{G} 5=100 ; \mathrm{C} 1=40 ; \mathrm{C} 2=100$. Conclusions: This in vitro study suggested that sodium hypochlorite-based substances and hydrogen peroxide are more efficient disinfectants against C. albicans than $2 \%$ chlorhexidine solution and the effervescent agent.
\end{abstract}

Key Words: Candida albicans. Denture cleaners. Acrylic resin.

\section{INTRODUCTION}

The presence of bacterial plaque and fungi are the main etiological factors of denture-induced stomatitis ${ }^{19}$. According to Ramage ${ }^{20}, 11 \%$ to $67 \%$ of complete denture users present candidiasis. Denture-induced stomatitis is characterized by the alteration of tissues under dentures, such as the presence of bright red colored areas and wrinkled surfaces ${ }^{12}$. Poor hygiene favors Candida albicans infection. Therefore, indication of denture cleansing is of paramount importance ${ }^{23}$.

The inner surface of dentures acts as a $C$. albicans reservoir, which is responsible for the beginning, progression and maintenance of the infection. Measures for controlling the colonization by this fungus may be adopted by the users of dentures ${ }^{12,22}$. A routine of cleaning may be instituted to prevent and remove the accumulation of microorganisms and to remove mucine, food remains, calculus and stains.

Denture cleaning may be achieved mechanically by brushing, chemically by use of chemical agents or by the association of both methods. Mc Callum, et al. ${ }^{15}$ affirmed that it is very difficult for dentists to recommend some sort of cleanser to their patients. Hence, patients themselves choose the product they will use without information about their benefits or risks. It is also important to point out that the cleaning agents employed must have the capacity to dissolve organic deposits, must not be toxic or irritate the mucosa, must be stable for storage, preferentially bactericidal and fungicide and must be harmless for the denture ${ }^{1,11}$.

Cleaning agents for dentures are classified as abrasive 
or chemical cleansers. Among the chemical agents, alkaline hypochlorites, peroxides and diluted acids may be cited ${ }^{16}$. Budtz-Jorgensen ${ }^{5}$ described the use of chlorhexidine for disinfection of dentures and for the treatment of candidiasis. Hypochlorite agents dissolve organic material, calculus and mucine, disinfect dentures and are good for stain removal. On the other hand, these agents are corrosive to metals and may be harmful for dentures when these are immersed in it for long periods ${ }^{21}$.

Alkaline peroxides, when dissolved in water, become alkaline hydrogen peroxide solutions. The degradation of peroxide liberates oxygen bubbles that mechanically clean dentures when in contact with debris. Such peroxides are recommended for the removal of mucine present in saliva and food remains and can also prevent the formation of stains and calculus ${ }^{3}$. They can be used as antimicrobial agents as well. However, they present the adverse effect of bleaching plastic materials.

Chlorhexidine was developed during the 1940s as the result of a research that intended to seek an antiviral agent but rather observed a remarkable antibacterial effect ${ }^{9}$. Characterized as a strong base, it is commonly prepared as the digluconate salt that confers to it a greater stability and water solubility. The use of chlorhexidine seems to be beneficial to patients with denture-induced stomatitis, but its continuous use causes the discoloration of acrylic resin and, therefore, should not be indicated for daily use $^{6}$.

Since the chemical method for disinfection of dentures is widely used by patients s $^{3,16}$ and as it is one of the processes for the treatment of candidiasis, this study was designed to evaluate the antifungal action of 5 denture cleaning chemical agents.

\section{MATERIAL AND METHODS}

Sixty specimens were fabricated with a heat-cured resin (Vipi Wave ${ }^{\circledR}$; VIPI, Pirassununga, SP, Brazil) according to manufacturer recommendations. Matrices $(10 \times 10 \times 5 \mathrm{~mm})$ were produced with a condensation silicone impression material (Zetalabor ${ }^{\circledR}$ (Zhermack S.p.A., Roviga, Italy). These matrices were invested in flasks, pressed and, after plaster setting, the matrices were removed and casts were obtained. The casts were coated with a thin layer of acrylic separating film (Cel-Lac $\AA$; S. S. White Artigos Dentários, Rio de Janeiro, RJ, Brazil), and were filled with plastic stage acrylic resin. The flasks were pressed slowly with a hydraulic presser until the excess material extruded from the borders, and were then opened for complete removal of the excess material. The flasks were again closed, taken to the hydraulic presser and pressed until both halves were again in contact, and then screwed. Polymerization procedures were performed, according to the cycle described by the manufacturer, which was of 20 min with at $180 \mathrm{~W}$ power output and $5 \mathrm{~min}$ with a $540 \mathrm{~W}$ power output. The specimens were removed after opening the flasks. No finishing and polishing procedures were done in order to simulate the inner surface of a complete denture. Only remaining excesses were removed with the aid of 320-grit wet sandpaper.

The specimens were immersed in distilled water in order to promote the maximum water sorption to prevent, when in culture, the occurrence of distortion and the release of residual monomer after polymerization ${ }^{4}$.

Pure cultures of $C$. albicans were grown on Agar Sabouraud plates (Oxoid, Basingstoke, UK) containing 500 $\mathrm{mMol} / \mathrm{L}$ of sucrose at $25^{\circ} \mathrm{C}$. After $24 \mathrm{~h}$, the colonies were suspended in tubes containing $5 \mathrm{~mL}$ of brain heart infusion (BHI) broth (Oxoid). The cell suspension in each tube was adjusted spectrophotometrically at $800 \mathrm{~nm}$ (O.D.800) to match the transmittance of $90 \mathrm{~T}$ (equivalent to $0.5 \mathrm{McF}$ arland scale $=1.5 \times 108 \mathrm{cfu}$ ). The $C$. albicans (R-68) strain was obtained from the Laboratory of Mycological research (LAPEMI) of the Department of Microbiology and Parasitology of the Federal University of Santa Maria, Brazil.

Next, the specimens were placed into the tubes containing BHI plus inoculum and remained for $11 \mathrm{~h}$ at $37^{\circ} \mathrm{C}$ in order to favor an initial colonization of the acrylic resin surfaces. The 60 specimens were distributed in 5 test groups and 2 control groups according to the disinfecting treatment to which they were subjected.

Each specimen was first washed with saline after immersion in the contaminated culture broth. Saline excess was removed with a gentle compression of sterile gauze. Then, the disinfection step was performed as follows: a) Control Group 1 (C1) - contaminated specimens, exposed to saline solution for $10 \mathrm{~min}$; b) Control Group 2 (C2) specimens without contamination, exposed to saline solution for 10 min; c) Group 1 (G1) - 2\% chlorhexidine solution for 10 min; d) Group 2 (G2) - 0.5\% sodium hypochlorite solution for $10 \mathrm{~min}$; e) Group 3 (G3) - modified hypochlorite (50\% v/v $0.5 \%$ hypochlorite solution and $96^{\circ} \mathrm{GL}$ alcohol) for $10 \mathrm{~min}$; f) Group 4 (G4) - Corega Tabs (GlaxoSmithKline, Brentford, United Kingdom) for 5 min; g) Group 5 (G5) - $10 \mathrm{v}$ hydrogen peroxide for $30 \mathrm{~min}$.

Each specimen was then washed again with saline and the excess was removed with sterile gauze. It was then transferred to individual tubes containing $5 \mathrm{~mL}$ of BHI broth + neutralizers, in order to prevent continued action of the disinfectants tested. The neutralizer for $\mathrm{NaOCl}$ was $0.6 \%$ sodium thiosulfate, while Tween 80 plus $0.07 \%$ lecithin was used for chlorhexidine. After $24 \mathrm{~h}$ of incubation, the tubes were individually transferred to a spectrophotometer at530 $\mathrm{nm}$ wavelength in order to measure the turbidity degree, through the transmittance. Aliquots of $10 \mathrm{iL}$ of each tube were then collected and inoculated into Agar Sabouraud plates (Oxoid) containing $500 \mathrm{mMol} / \mathrm{L}$ of sucrose, which were incubated for $24 \mathrm{~h}$ at $37^{\circ} \mathrm{C}$, in order to check microbial growth. The purity of the positive cultures was confirmed by Gram staining, by colony morphology on agar plates and by the use of biochemical identification kits (API 20 C Aux, BioMérieux, Marcy l'Étoile, France, for yeast identification).

The results obtained were statistically treated using the software SPSS 10.0 for Windows (SPSS Inc., Chicago, IL, USA) using the Kruskal-Wallis test, with significance level set at $\mathrm{p}<0.05$. 


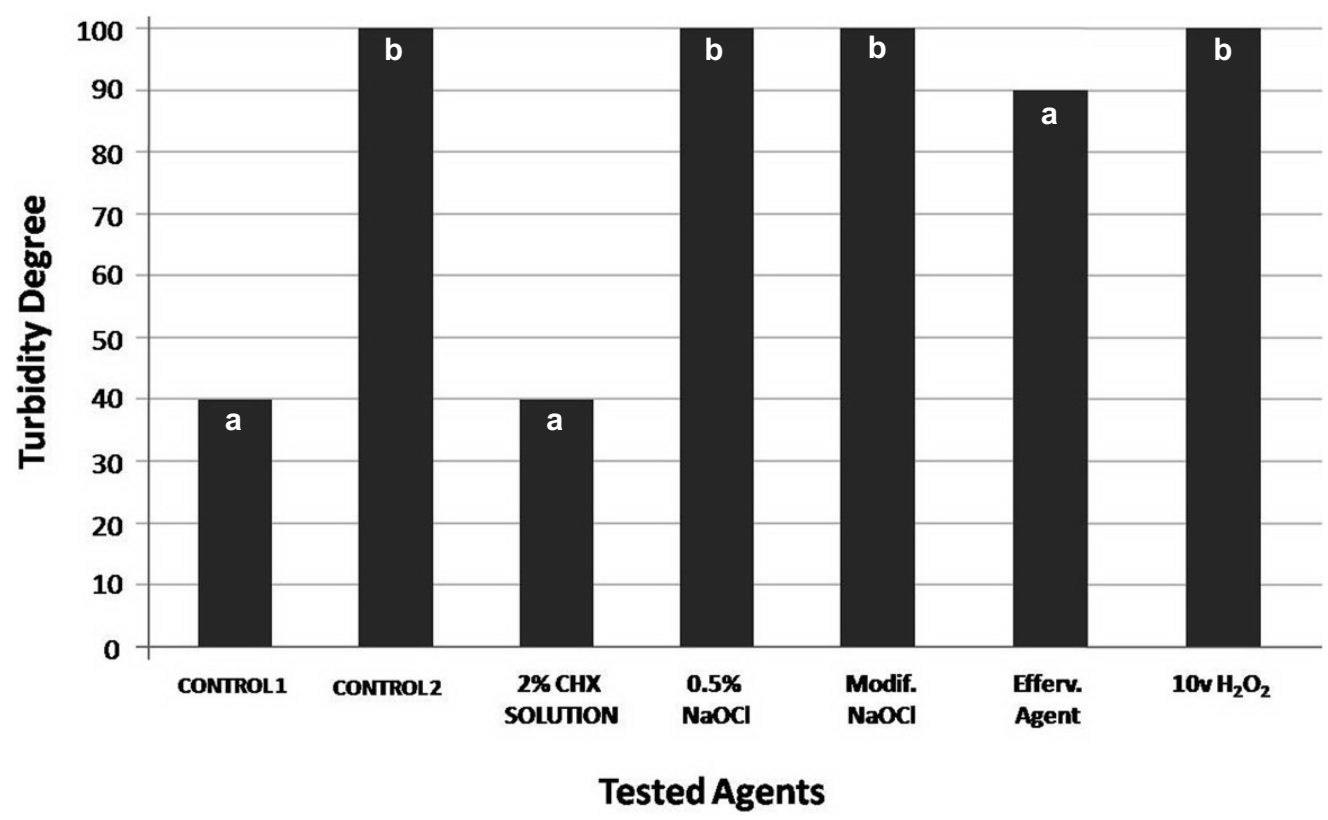

FIGURE 1- Medians of the turbidity degrees for all tested groups $(n=10)$. Different letters mean statistically significant difference

\section{RESULTS}

Figure 1 shows the antimicrobial activity of each chemical agent. The greater the transmittance values the better the antimicrobial action. The results of the spectrophotometer measurements were represented by medians and minimum and maximum values, as follows: G1 $-2 \%$ chlorhexidine solution $=40$ (minimum $=60$, maximum $=20) ; \mathrm{G} 2-0.5 \%$ sodium hypochlorite $=100$ $($ minimum $=100$, maximum $=80) ; \mathrm{G} 3-$ Modified sodium hypochlorite $=100($ minimum $=100$, maximum $=90) ; \mathrm{G} 4$ - effervescent agent $=90$ (minimum $=100$, maximum $=$ 60 ); G5 - 10 volumes hydrogen peroxide $=100$ (minimum $=100$, maximum $=80) ; \mathrm{C} 1-$ specimens without disinfecting agents $=40 ; \mathrm{C} 2-$ specimens without contamination $=100$.

Microbial growth and the purity of the growth were checked after $24 \mathrm{~h}$ by inoculating $10 \mu \mathrm{L}$ of the suspension medium in agar plates to certify that the transmittance values achieved were due to the Candida growth and not to any potential contamination during the procedures. Chlorhexidine solution and the non-disinfected specimens did not inhibit the growth of the target microorganism, as observed by the microbial growth on the agar plates.

\section{DISCUSSION}

Oral environment temperature and the acquired pellicle formed over dentures promote Candida albicans adhesion to resin materials, indicating the need of an adequate plaque control for maintaining oral health ${ }^{18}$. Chandra, et al. ${ }^{7}$ showed that the development of this yeast on acrylic resins happens in three distinct stages: initial stage - up to $11 \mathrm{~h}$ from the colonization, when some micro-colonies begin to be formed; intermediate stage - from 12 to $30 \mathrm{~h}$ after colonization, when extracellular material begins to accumulate over colonies; and maturation stage - from 38 to $72 \mathrm{~h}$ after colonization, when Candida colonies become totally involved by the extracellular matrix forming a biofilm. They also concluded that antifungal resistance increases during biofilm development, as the extracellular matrix acts as a barrier to the action of the antifungal.

In the present study, the $0.5 \%$ hypochlorite and the modified hypochlorite solution were able to eliminate $C$. albicans from the resin surface. Several studies showed that $0.5 \%$ sodium hypochlorite solution had excellent results regarding C. albicans removal ${ }^{2,6,8,14,16,21}$. According to Chau, et al. ${ }^{8}$, a 10 -min immersion in $5.25 \%$ sodium hypochlorite solution is effective for the disinfections of both the external and internal surfaces of the acrylic resin. However, hypochlorite use must be recommended only once a week as it bleaches and damages acrylic resin ${ }^{6}$. Further studies are necessary to elucidate the action of the modified sodium hypochlorite and to determine its effect on acrylic resins.

Hydrogen peroxide agents promote oxidation and also liberate oxygen during their degradation, with simultaneous chemical and mechanical actions. The peroxide products used in this research showed different results. The $10 \mathrm{~V}$ hydrogen peroxide was efficient when used during $30 \mathrm{~min}$. On the other hand, Corega Tabs ${ }^{\mathrm{TM}}$, used during $5 \mathrm{~min}$, as recommended by the manufacturer, did not show the same efficiency. The manufacture's information suggests that plaque remaining after the immersion period recommended is not enough for stomatitis development ${ }^{21}$. However, according to literature, these products are ineffective during short immersion periods ${ }^{17}$. Budtz-Jorgensen ${ }^{6}$ related the advantages of effervescent products to the fact that they are safe and do not damage acrylic resin even when constantly used.

Iacopino, et al. ${ }^{12}$ reported that chlorhexidine is highly effective against denture-induced stomatitis. Its effect as mouth rinsing agent during the treatment can be observed 
in the oral mucosa covered by the prosthetic device, allowing a better tissue conditioning and healing. Chlorhexidine destroys bacteria by breaking their membrane and inducing citoplasmatic precipitation ${ }^{10,13}$. The chlorhexidine cationic molecule is capable of interacting with inorganic human dentine particles and also bonds to negatively charged surfaces, such as the bacterial cellular wall. In the present study, this substance was not effective against Candida albicans. This lack of antimicrobial action might be justified by the concentrations and immersion periods used. Pavarina, et al. ${ }^{19}$ recommend the use of $4 \%$ chlorhexidine for $10 \mathrm{~min}$ to disinfect complete dentures. Moreover, alike the substrates that chlorhexidine can bind, acrylic resin is an organic compound of non-ionic charged particles. Then, higher concentrations of chlorhexidine for disinfecting prosthetic devices and its topic effect as mouth rinse could act simultaneously for best treating stomatitis associated with fungi.

Chemical methods may be recommended for patients with candidiasis to complement the cleaning of acrylic resin dentures ${ }^{11}$. The results of the present study suggested $0.5 \%$ sodium hypochlorite- or $10 \mathrm{~V}$ hydrogen peroxide-based products as disinfecting agents for dentures because they are affordable and show adequate antifungal action.

The knowledge of denture cleansing techniques is important to dental surgeons, as there are several solutions available on the market promising to clean and disinfect dentures in short periods. The dentist should be able to suggest an efficient method that does not damage the denture material and is safe for the patient ${ }^{23}$.

\section{CONCLUSIONS}

Based on the results, it may be concluded that the tested agents containing sodium hypochlorite or $10 \mathrm{~V}$ hydrogen peroxide in their composition showed excellent antifungal action. The effervescent agent used according to the manufacturer's instructions was not effective in removing C. albicans colonies. Moreover, $2 \%$ chlorhexidine solution was not effective up to $10 \mathrm{~min}$ immersion.

\section{REFERENCES}

1- Abelson DC. Denture plaque and denture cleansers: review of the literature. Gerodontics. 1985;1:202-6.

2- Arita M, Nagayoshi M, Fukuizumi T, Okinaga T, Masumi S, Morikawa $\mathrm{M}$, et al. Microbicidal efficacy of ozonated water against Candida albicans adhering to acrylic denture plates. Oral Microbiol Immunol. 2005;20:20610

3- Antony DH, Gibbons P. The nature and behavior of denture cleansers. J Prosthet Dent. 1958;8:797-810.

4- Braun KO, Mello JA, Rached RN, Del Bel Cury A. Surface texture and some properties of acrylic resins submitted to chemical polishing. J Oral Rehabil. 2003;30:91-8.
5- Budtz-Jorgensen E, Loe H. Chlorhexidine as a denture disinfectant in treatment of denture stomatitis. Scand J Dent Res. 1972;80:457-64.

6- Budtz-Jorgensen E. Materials and methods for cleaning dentures. J Prosthet Dent. 1979;42:619-23.

7- Chandra J, Kuhn DM, Mukherjee PK, Hoyer LL, McCormick T, Ghannoum MA. Biofilm formation by the fungal pathogen Candida albicans: development, architecture, and drug resistance. J Bacteriol. 2001;183:5385-94.

8- Chau VB, Saunders TR, Pimsler M, Elfring DR. In-depth disinfection of acrylic resins. J Prosthet Dent. 1995;74:309-13.

9- Fardal O, Turnbull RS. A review of the literature on use of chlorhexidine in dentistry. J Am Dent Assoc. 1986;112:863-9.

10- Gomes BPFA, Vianna ME, Matsumoto CU, Rossi V P, Zaia AA, Ferraz $\mathrm{CC}$, et al. Disinfection of gutta-percha cones with chlorhexidine and sodium hypochlorite. Oral Surg Oral Med Oral Pathol Oral Radiol Endod. 2005;100:512-7.

11- Hutchins DW, Parker WA. A clinical evaluation of the ability of denture cleaning solutions to be remove dental plaque from prosthetic devices. $\mathrm{N}$ Y State Dent J. 1973;39:363-7.

12- Iacopino AM, Wathen WF. Oral candidal infection and denture stomatitis: a comprehensive review. J Am Dent Assoc. 1992;123:46-51.

13- Jenkins S, Addy M, Wade W. The mechanism of action of chlorhexidine: a study of plaque growth on enamel inserts in vivo. J Clin Periodontol. 1988;15:415-24.

14- Langwell WH. The cleansing of artificial dentures. Br Dent J. $1955 ; 15: 337-9$

15- Mc Callum M, Stafford GD, MacCulloch WT, Combe EC. Which cleanser? Dent Pract. 1968;19:83-9.

16- Neilli DJ. A study of materials and methods employed in cleaning dentures. Br Dent J. 1968;124:107-15.

17- Nikawa H, Hamada T, Yamashiro H, Kumagai H. A review of in vitro and in vivo methods to evaluate the efficacy of denture cleansers. Int J Prosthodont. 1999;12:153-9.

18- Nikawa H, Chen J, Hamada T, Nishimura M, Polyzois G. Candida albicans colonization on thermal cycled maxillofacial polymeric materials in vitro. J Oral Rehabil. 2001;28:526-33.

19- Pavarina AC, Pizzolitto AC, Machado AL, Vergani CE, Giampaolo ET. An infection control protocol: effectiveness of immersion solutions to reduce the microbial growth on dental prostheses. J Oral Rehabil. $2003 ; 30: 532-6$

20- Ramage G, Tomsett K, Wickers BL, López-Ribot J, Redding SW. Denture stomatitis: a role for Candida biofilms. Oral Surg Oral Med Oral Pathol Oral Radiol Endod. 2004;98:53-9.

21- Requa-Clark B. Denture cleansers: council on dental materials, instruments, and equipament. J Am Dent Assoc. 1983;106:77-9.

22- Samaranayake LP, McCoutie J, Mac Farlane TW. Factors affecting the in vitro adherence of Candida albicans to acrylic surfaces. Arch Oral Biol. 1980;25:611-5.

23- Shay K. Denture hygiene: a review and update. J Contemp Dent Pract. $2000 ; 15: 28-41$ 